\title{
A CATEGORIZAÇÃO DE EDUCAÇÃO AMBIENTAL: DISCUSSÕES DE PROPOSTAS, PROCESSOS E FINALIDADES A PARTIR DA PERCEPÇÃO DE UM GRUPO DE PÓS-GRADUANDOS
}

\author{
THE CATEGORIZATION OF ENVIRONMENTAL EDUCATION: PROCESS OF PROPOSALS, PROCESSES \\ AND PURPOSES FROM THE PERCEPTION OF A GROUP OF GRADUATE STUDENTS
}

\author{
KARINA BRACCINI PEREIRA ${ }^{1}$ \\ MAURÍCIO CENDÓN DO NASCIMENTO ÁVILA \\ AILTON JESUS DINARDI ${ }^{3}$ \\ EDWARD FREDERICO CASTRO PESSANO ${ }^{4}$
}

\section{RESUMO}

A Educação Ambiental muitas vezes ocorre como ação secundária no processo de formação, não havendo inserção integrada e interdisciplinar. Assim, o objetivo deste estudo é categorizar conceitos de educação ambiental, inter-relacionando interdisciplinaridade e temas transversais, de discentes de Especialização em Educação Ambiental, à luz da Análise Textual Discursiva (ATD), como avanço metodológico, em relação às categorizações de Layrargues e Lima (2014). Esta pesquisa foi desenvolvida em 2019, na Universidade Federal do Pampa, classificando-se como exploratória. Para coleta de dados aplicou-se questionário, respeitando o caráter anônimo e voluntário. Através da classificação de Layrargues e Lima identificou-se dificuldade em categorizar as percepções dos discentes integralmente. A utilização da ATD permitiu analisar o todo em partes, percebendo-se impossibilidade de classificar o pensamento do indivíduo em categoria única. As categorias finais da ATD só foram possíveis de serem construídas a partir dos excertos advindos dos discursos, demonstrando que nossa expressão é algo em formação.

Palavras-Chave: Temática Ambiental. Classificação. Análise Textual Discursiva. Inter-relações. Formação Docente.

\section{ABSTRACT}

Environmental Education often occurs as a secondary action in the training process, with no integrated and interdisciplinary insertion. Thus, this study objective was to categorize environmental education concepts, interrelating interdisciplinarity and transversal themes, of students from the Specialization in Environmental Education, in the light of Discursive Textual Analysis (DTA), as methodological advance, in relation to the categorizations by Layrargues and Lima (2014). This research was developed in 2019, at the Federal University of Pampa and is classified as explorator. For data collection, questionnaire was applied, respecting the anonymous and voluntary nature. Through the classification by Layrargues and Lima, it was identified a difficulty in categorizing the students' perceptions in full.The use of DTA allowed us to analyze the whole in parts, realizing impossibility of classifying the individual's thinking in a single category. The final categories of DTA were only possible to be built from the excerpts from the speeches, demonstrating that our expression is something in constant formation.

Keywords: Environmental Thematic. Classification. Discursive Textual Analysis. Interrelationships. Teacher Education.

\footnotetext{
1 Doutoranda em Educação em Ciências e Técnica de Laboratório de Biologia da Universidade Federal do Pampa, campus Uruguaiana/RS E-mail: karinapereira@unipampa.edu.br. ORCID: https://orcid.org/0000-0003-1163-1046.

2 Mestre em Educação em Ciências pela Universidade Federal do Pampa, Uruguaiana/RS. Email:mcn.avila@gmail.com. ORCID: https://orcid.org/ 0000-0002-6241-9697.

3 Doutor em Ciências Florestais pela Universidade Estadual de São Paulo. Professor Adjunto da Universidade Federal do Pampa, Uruguaiana/RS. E-mail: ailtondinardi@unipampa.edu.br. ORCID: https://orcid.org/0000-0002-5625-1787.

4 Doutor em Educação em Ciências pela Universidade de Santa Maria. Professor Adjunto da Universidade Federal do Pampa, Uruguaiana/RS. E-mail: edwardpessano@unipampa.edu.br. ORCID: https://orcid.org/0000-0002-6322-6416.
} 


\section{INTRODUÇÃO}

A Educação Ambiental (EA), apesar de tão necessária para a formação de uma sociedade ética e compromissada com as questões socioambientais e de sustentabilidade, pode ser observada muitas vezes, como uma ação secundária ao processo de formação dentro dos espaços escolares; onde habitualmente se delega a apenas algumas disciplinas, como Ciências e Biologia, a responsabilidade pelas discussões e reflexões acerca da temática, não havendo a devida preocupação com a sua inserção efetiva, integrada e interdisciplinar junto às práticas educativas.

Entretanto, atualmente verifica-se ser cada vez mais imprescindível que as instituições de ensino, sendo estas uma base de referência na sociedade, oportunizem a formação de cidadãos e cidadãs críticos e ambientalmente conscientes. Infelizmente, conforme Coimbra (2011) as fragilidades são inúmeras em relação à EA, especialmente no ensino superior tanto em termos quantitativos, como qualitativos. E segundo Grün (1996) uma educação que não for ambiental, não poderá ser considerada educação de jeito nenhum.

Estes aspectos vão ao encontro do que a própria legislação preconiza, pois de acordo com a Lei Federal $n^{0}$ 9.795/99, que institui a Política Nacional de Educação Ambiental, em seu artigo $10^{\circ}$ registra que "a educação ambiental será desenvolvida como prática educativa integrada, contínua e permanente em todos os níveis e modalidades do ensino formal" e deverá perpassar todas as áreas do conhecimento (BRASIL, 1999).

Quando a legislação apresenta a EA como uma prática educativa integrada, contínua e permanente, pode haver a sensação de que esta prática é algo linear, com um modelo de pensamento único, homogêneo, e com certo equilíbrio de discurso. Porém, Layrargues e Lima (2014, p. 28) informam que:

[...] se 0 campo da Educação comporta várias correntes pedagógicas; se 0 campo do ambientalismo desenvolveu uma diversidade de correntes de pensamento ao longo dos seus mais de quarenta anos; se o próprio conceito de Sociedade contempla abordagens diferentes, não é difícil imaginar que a confluência desses inúmeros feixes interpretativos que moldam a Educação Ambiental produziria um amplo espectro de possibilidades de se conceber a relação entre a educação e 0 meio ambiente. Inevitavelmente, era questão de tempo e amadurecimento do campo para que essa possibilidade se tornasse uma realidade. Na prática, isso significa que existem muitos caminhos possíveis de conceber e realizar os meios e os fins da Educação Ambiental.

Reigota (2004) apresenta definições de vários especialistas de diferentes ciências sobre essa área do conhecimento, que segundo o seu ponto de vista indicam que não existe um consenso sobre o tema na comunidade científica em geral; portanto, para ele, a noção de meio ambiente é uma representação social. Segundo Silva et al. (2014) Reigota observou a diversidade existente entre opiniões de diferentes especialistas quando se referem ao conceito de meio ambiente, notando que o termo é definido conforme as áreas de atuação. Assim, considera que a formação é um fator contribuinte para a construção do conceito referente ao tema.

Ainda para Silva et al. (2014), a universidade tem responsabilidade na formação profissional e cidadã dos acadêmicos, os quais desempenham seus papéis em múltiplas áreas sociais, levando consigo a compreensão adquirida durante a formação acadêmica. Além disso, carregam concepções 
e ideias formadas durante a vida, que contribuem direta e indiretamente no entendimento e comportamento diante das questões ambientais presentes na sociedade.

Ao longo do tempo uma série de pesquisadores (FERNANDES et al., 2002; TOZONI-REIS, 2003; SAUVÉ, 2006; LOUREIRO, 2007 e LAYRARGUES \& LIMA, 2014) procuraram descrever tendências, ações e posicionamentos dos educadores sobre EA, em função de suas escritas e projetos desenvolvidos. Se por um lado esta categorização é importante enquanto processo de estudo e reflexão, apontando um campo social plural, por outro lado, mesmo sem ser o objetivo inicial desses autores, a criação dessas categorias acaba sendo usada para 0 enquadramento dos sujeitos pesquisados em classes, que podem parecer estanques e acabar por criar certos "rótulos" de posicionamento. Como se a educação fosse algo pronto e acabado e que os educadores, por exemplo, com uma visão naturalista em um determinado momento de sua trajetória, não pudessem migrar ao longo do seu processo formativo, para uma forma de pensamento mais crítico.

Segundo Nascimento (2009), as representações de estudantes, professores, gestores, educadores ambientais e outros grupos levantam indícios de que se torna imperativo desenvolver trabalho pedagógico efetivo que possa oferecer subsídios a tais grupos para que passem a conceber o meio ambiente de uma forma mais abrangente, incluindo os aspectos naturais (biológicos), políticos, sociais, econômicos, históricos e éticos.

E complementa dizendo:

Investigações acerca das representações sociais são de grande relevância para obtenção de dados sobre como o conhecimento científico é comunicado e compreendido no cotidiano sob a lógica do senso comum por determinado grupo de pessoas. Portanto, recomendamos, ao se trabalhar com representações na área de educação científica, não usar qualificações do tipo certo e errado para os resultados obtidos, por estarmos lidando com conhecimento do senso comum (NASCIMENTO, 2009, p. 10).

Diante dessas constatações de que as concepções ambientais são representações sociais, que a categorização dessas representações podem causar segregações, se usadas com o intuito de qualificar e depreciar as práticas de EA, uma forma dinâmica de categorização das representações sociais, pode ser alcançada com o uso da Análise Textual Discursiva - ATD de Moraes e Galiazzi (2007). Apresenta-se a ATD para produzir compreensões sobre discursos, ou seja, poderá proporcionar ao processo de categorização das representações de EA um aspecto de caminhada, de construção dinâmica, que não é neutra, mas que expressa a visão e concepções, que pode apresentar várias facetas de representação social, mas que não é algo pronto e estanque.

Neste cenário, a instituição objeto do presente estudo, Universidade Federal do Pampa (Unipampa), foi criada como um resultado da reivindicação da comunidade regional, da "Metade Sul" do Rio Grande do Sul. Região esta que abrange o Bioma Pampa e está estruturada em dez campi. No Campus Uruguaiana é ofertado além dos cursos de graduação, diversos cursos de pós-graduação, Stricto e Lato sensu, dentre estes a Especialização em Educação Ambiental.

Considerando 0 exposto, 0 objetivo desta pesquisa é propor a categorização das concepções de educação ambiental, bem como suas inter-relações com a interdisciplinaridade e os temas transversais, a partir das percepções conceituais de um grupo de discentes do curso de Especialização em Educação Ambiental, à luz da ATD, como um avanço metodológico, em relação às categorizações ofertadas por Layrargues e Lima (2014). 


\section{ABORDAGEM METODOLÓGICA}

0 presente estudo foi desenvolvido no ano de 2019, na Universidade Federal do Pampa-Unipampa, Campus Uruguaiana/RS, com discentes do curso de Especialização em Educação Ambiental. Este campus concentra quatro cursos de Doutorado, cinco cursos de Mestrado Acadêmico, quatro de Especialização em andamento e oito de Graduação, totalizando no momento de coleta de dados desta pesquisa, 1986 (mil novecentos e oitenta e seis) discentes na Graduação e 359 (trezentos e cinquenta e nove) na Pós-graduação, atendidos por 101 (cento e um) técnicos administrativos em educação (TAEs) e 183 docentes, conforme os dados disponibilizados pelo Sistema de Informação para o Ensino (SEI) da Unipampa.

Os procedimentos metodológicos utilizados classificam esta pesquisa como exploratória, com abordagem qualitativa. Este tipo de pesquisa, segundo Oliveira (2007, p. 65) "objetiva dar uma explicação geral sobre determinado fato, através da delimitação do estudo, levantamento bibliográfico, leitura e análise de documentos". Ainda segundo 0 autor, este tipo de pesquisa desenvolve estudos que dão uma visão geral do fato ou fenômeno estudado.

Para a coleta dos dados produziu-se um questionário, com três questões abertas, o qual foi aplicado aos participantes da investigação. Estes questionamentos visam à obtenção de informações que contribuam nas análises com relação às discussões e reflexões sobre a temática ambiental, sendo que foi respeitado o caráter anônimo e voluntário da participação, onde informaçõ̃es pessoais não foram solicitadas.

As referidas questões foram estruturadas, visando abordar a ótica destes discentes sobre a EA, conforme abaixo:

Qual sua concepção de Educação Ambiental? 2. Qual sua definição de Interdisciplinaridade? 3. 0 que você entende que sejam temas transversais? Exemplifique.

Os estudantes participantes da pesquisa, 18 indivíduos, foram denominados pela letra (A), seguidos de uma numeração sequencial, A1, A2,... A18.

Os dados foram analisados qualitativamente, de acordo com as Macrotendências Político-pedagógicas da Educação Ambiental Brasileira de Layrargues e Lima (2014) e através da Análise Textual Discursiva - ATD de Moraes e Galiazzi (2007).

Segundo Layrargues e Lima (2014, p. 24) há um debate que polariza duas interpretações sobre a necessidade da formação e diferenciação das correntes político-pedagógicas na EA:

[...] a primeira julga que os riscos da análise são maiores que os ganhos, porque entende que as tipologias simplificam a realidade, perdem de vista seu dinamismo e induzem a um estranhamento entre os atores sociais que compartilham o campo. A segunda julga que os benefícios da análise superam esse risco: não se trataria aqui de um esforço gratuito de abstração, mas de uma interpretação da realidade que traz resultados positivos.

Apesar do registro desta polarização, os autores em questão optam pela categorização que denominam de macrotendências, discutindo e apontando suas características, classificando-as como Macrotendência Conservacionista, Macrotendência Pragmática e Macrotendência Crítica.

A Análise Textual Discursiva - ATD pode ser entendida e descrita como: 
[...] processo que inicia com a unitarização em que textos são separados em unidades de significado. Estas unidades podem gerar outros conjuntos de unidades oriundas da interlocução empírica, teórica e das interpretações do pesquisador. Neste movimento de interpretação do significado atribuído pelo autor exercita-se a apropriação das palavras de outras vozes para compreender melhor o texto. Depois da realização da unitarização, passa-se a fazer articulação de significados semeIhantes em um processo denominado de categorização. Neste processo reúnem-se as unidades de significado semelhantes, podendo gerar várias categorias de análise; gerando metatextos analíticos que irão compor os textos interpretativos (MORAES e GALIAZZI, 2006, p. 118).

Ao apropriar-se do texto produzido pelos sujeitos da pesquisa e analisá-los através de dois instrumentos de análise, pretende-se ressaltar a ATD enquanto ferramenta que possibilita levar em consideração no processo de escrita, as múltiplas facetas do indivíduo e a sua complexidade, em detrimento da categorização mais "dura", estática, imutável, que não permite 0 olhar para 0 aprendizado e a formação enquanto processo.

\section{RESULTADOS E DISCUSSÃO}

Os 18 estudantes participantes do estudo foram os que se manifestaram como voluntários e estavam presentes no dia que o questionário foi aplicado, de um total de 23 estudantes matriculados, representando $78 \%$ da população objetivada.

\section{Análise das concepções através das Macrotendências de Layrargues e Lima (2014)}

Após a análise, com relação à percepção conceitual de EA pode-se inferir que as respostas trazem diferenças consideráveis entre 0 grupo investigado. As diferenças apresentadas nos remetem à importância da discussão das questões ambientais, principalmente levando em consideração as distintas áreas do conhecimento, reflexo da diversidade na formação inicial destes discentes.

Neste sentido, de acordo com Sauvé (2005, p. 1):

Quando se aborda o campo da Educação Ambiental, podemos nos dar conta de que, apesar de sua preocupação comum com o meio ambiente e do reconhecimento do papel central da educação para a melhoria da relação com este último, os diferentes atores adotam diferentes discursos sobre a EA e propõem diversas maneiras de conceber e de praticar a ação educativa neste campo.

De fato, não existe um consenso nas definições de meio ambiente, seja na comunidade científica ou fora dela. As particularidades do termo levam a uma concepção muitas vezes difusa, o que acarreta uma incompreensão do verdadeiro sentido da EA (OLIVEIRA, 2007).

No entanto, houve consenso entre os discentes, quanto à necessidade e à relevância das discussões sobre as questões ambientais e a sustentabilidade em sua formação, como discente e profissional, podendo-se observar no registro de A2: 
"A Educação Ambiental está ligada a comportamento, reflexão das ações cotidianas e atuação diante dos impactos que estamos enfrentando, para que promova mudanças".

Segundo Coimbra (2011), o conceito de meio ambiente e EA foi reduzido, durante um longo período, a um enfoque naturalista, priorizando apenas a vida biológica e a natureza, com esta sendo tratada de forma independente da interação com o mundo; onde aspectos sociais, políticos, culturais e econômicos e suas interações, não estavam contemplados pelo conceito. Isso acarretou, e ainda acarreta fortemente, a desnaturalização do ser humano, que passa a acreditar que os recursos estão disponíveis para serem utilizados, numa visão predominantemente antropocêntrica.

Ao longo de sua história a EA recebeu várias denominações; no Brasil, esta prática educativa instituída na década de 1980, possuía enfoque estritamente ambiental. Conforme Lima (2009), também nesta década, a educação popular instituída por Freire, começou a exercer grande influência sobre EA rompendo com a tradicional concepção tecnicista da educação, de simples repasse do conhecimento.

Atualmente a EA compreende múltiplas vertentes ou correntes, com conceitos, práticas e metodologias próprias, não diferenciadas facilmente. Dentre suas denominações pode-se citar: EA popular, crítica, política, comunitária, formal, não formal, para o desenvolvimento sustentável, conservacionista, socioambiental, ao ar livre, entre outras (CARVALHO, 2004). Apesar de tantas denominações, para o público não especializado a EA geralmente aparece, segundo Layrargues (2012), com objetivo de conscientizar as pessoas com relação a problemas estritamente ecológicos. Caracterizando uma única vertente predominante, com visão tradicional, a qual poderia ser identificada como Conservadora ou Pragmática.

Na concepção de Sauvé (2005), uma das estratégias de apreensão das diversas possibilidades teóricas e práticas no campo da EA consiste em elaborar um mapa deste "território" pedagógico. Trata-se de reagrupar proposições semelhantes em categorias, de caracterizar cada uma destas e de distingui-las entre si. Em sua sistematização, a autora explora 15 correntes de EA.

Entretanto, ao analisar o discurso dos estudantes foi possível encontrar mais subsídios para discussão dos resultados obtidos quando se considerou as macrotendências (Conservacionista, Pragmática e Crítica) de Layrargues e Lima (2014), que se diferenciam principalmente por seus objetivos com relação ao meio ambiente e à sociedade.

Neste sentido, salienta-se o conceito de Campo Social de Bourdieu (2001, 2004), como sendo um espaço relativamente autônomo de forças e posições sociais, dotado de regras próprias e dedicado à produção e reprodução de bens culturais, representações e formas de perceber a realidade. A noção de Campo Social permite vislumbrar as normas, os valores, os interesses, sistemas simbólicos e objetivos que orientam um espaço social, além, evidentemente, dos conflitos que dão a medida de sua diversidade interna e da dinâmica das forças sociais que o movimenta (BONNEWITZ, 2003).

Diferenciar internamente um campo social tem como objetivos analisar e interpretar fenômenos ou processos que são diferentes entre si, mas com alguma semelhança ou elementos comuns, podendo ser percebidos como homogêneos, como o que ocorre nas questões ambientais. Além disso, a tarefa analítica contribui para 0 aprofundamento da auto reflexividade do campo da EA. A decomposição analítica daquilo que parecia ser um todo homogêneo permite perceber diferenças internas e identificar motivações, interesses e valores que inspiraram sua constituição diversa, no caso, as macrotendências político-pedagógicas da educação ambiental de Layrargues e Lima (2014). 
A esse respeito, Bertolucci, Machado e Santana (2005), constatando a dominância da percepção da EA como uma prática educativa homogênea (devido a certas semelhanças ou elementos comuns), concordam com a necessidade de se repensar um campo social, o que implicaria em ganhos de amadurecimento teórico e epistemológico não apenas do campo, mas também de cada vertente político-pedagógica. A necessidade de compreender as singularidades do campo parece ser um caminho sem volta.

Macrotendência Conservacionista - A EA de caráter conservacionista se estabeleceu devido a uma lógica de sensibilidade humana em relação à natureza, ou seja, a face mais visível da crise ambiental foi a destruição do meio ambiente, e as ciências que tratavam do assunto (ambientais), não compreendiam questões sociais em seus pressupostos. Atua, por exemplo, como trilhas interpretativas, dinâmicas agroecológicas e de senso de percepção; ocorre comumente em unidades de conservação e atividades de ecoturismo. Esta vertente tem forte relação com crianças em idade escolar e apresenta como objetivo trabalhar o amor pela natureza (LAYRARGUES \& LIMA, 2014). Dentre os registros pode-se categorizar como Conservacionistas as manifestações de:

A1: "Educação Ambiental é uma forma de relação do ser humano com o todo. De sensibilização, pertencimento e principalmente reconstrução".

A10: "Educação Ambiental significa o indivíduo se sentir pertencente ao meio, se sentindo desta maneira passando a cuidar e preservar o ambiente, visando uma melhor qualidade de vida".

A18: "É uma dimensão no qual todos nós estamos inseridos como pertencentes a um todo, onde cada um tem suas obrigações para manter esse todo em equilibrio".

Esta macrotendência permaneceu dominante até a década de 1990, quando surgiu a vertente pragmática. No entanto, apesar de não ser mais dominante, é uma tendência fortemente consolidada historicamente (LAYRARGUES, 2012). Em comparação, segundo classificação de Fernandes et al. (2002), essas falas dos discentes se enquadram na categoria "Tradicional", demonstrando uma ótica ainda conservadora e prioritariamente biológica, por muitas vezes com um viés utilitarista.

Macrotendência Pragmática - Segundo Guimarães (2004), a vertente que ainda não supera 0 antropocentrismo, apresentando uma visão fragmentada do mundo, característica da modernidade, é denominada pragmática. É amplamente divulgada ao consumidor, dando-lhes a responsabilidade de cuidar do meio ambiente; é permeada pela ideia do individual, expressa pela noção de que "cada um deve fazer a sua parte".

Layrargues (2012) afirma que, assim como a conservacionista, a pragmática também está ligada à faixa etária infantil, no entanto, trabalha com a ideia de um planeta limpo para as próximas gerações. Ainda conforme 0 autor, a pragmática é considerada uma derivação da conservacionista, mas, adaptada ao atual contexto socioeconômico e tecnológico da sociedade. Para melhor elucidar, em sua terminologia equivalente, Fernandes et al. (2002) denominam como "Resolução de Problemas", a qual teria um foco atuante em questões pontuais da crise ambiental; geralmente desconsiderando os efeitos causais, as consequências e os impactos socioambientais.

Dentre os registros podem-se categorizar como Pragmáticas manifestações de:

A2: "A Educação Ambiental está ligada a comportamento, reflexão das ações cotidianas e atuação diante dos impactos que estamos enfrentando, para que promova mudanças". 
A13: "A educação ambiental, como o próprio nome diz, se refere a ensinar o indivíduo a cuidar do ambiente onde está inserido. Seja ele o ambiente de trabalho, em casa, na escola, no parque. Conscientizar o homem a respeitar outras formas de vida é educação ambiental. Cuidar da gestão de uma empresa é educação ambiental. Reciclar, cuidar do ambiente é educação ambiental. Respeito é educação".

A15: "Educação Ambiental ter novos conhecimentos para poder transmitir, o resultado seja multiplicado, trabalho coletivo, mudanças de hábitos e costumes, para uma melhoria".

Esta poderia até adquirir um caráter crítico se incorporasse ao seu discurso análises sociais, econômicas, culturais e políticas, na problemática dos resíduos sólidos do atual modelo de desenvolvimento, por exemplo. No entanto, além de não considerar a relação entre os problemas ambientais e suas causas, tenta resolvê-los de forma imediata não se importando com o que ou quem foi responsável por determinada situação (LAYRARGUES \& LIMA, 2014).

Macrotendência Crítica - Por fim, a vertente crítica é citada, por alguns autores, como sinônimo de EA transformadora, popular, emancipatória e dialógica (LOUREIRO, 2007; LIMA, 2009). Isto possivelmente, pois uma educação crítica se origina de ideias democráticas e emancipatórias da educação popular, sendo contrária à educação tecnicista, com a simples transmissão de conhecimento. Uma das principais referências da educação crítica é Paulo Freire (1979), o qual insiste na educação formadora de cidadãos emancipados, autores de suas próprias histórias (CARVALHO, 2004).

Na concepção de Layrargues e Lima (2014, p. 29) "a crise ambiental não expressava problemas da natureza, mas problemas que se manifestavam na natureza"; a EA Crítica pode ser considerada a EA almejada atualmente, pois defende a importância de incluir nos debates as ideias político-ideológicas do sistema de reprodução social e a inter-relação sociocultural do ser humano com a natureza.

Na categorização de Fernandes et al. (2002), esta é classificada como "integradora", a qual pode conferir aos atores sociais envolvidos autonomia para observar e analisar ações do seu cotidiano; e nesta investigação, pode-se categorizar como Críticos, as manifestações de:

A3: "Educação Ambiental na minha concepção tem um universo maior que preservar/conservar/reciclar, na minha visão educação ambiental tem uma dimensão política, social, cultural, tudo que envolve o meio onde estamos inseridos, não só o ambiente, mas a casa, a escola, a sociedade como um todo; 0 aprender e compreender o que é, como fazer, respeitando as diferentes vivências e opinióes de cada um".

A7: "Educação Ambiental na minha concepção é uma forma de educar de uma maneira global, de inserir o educando no contexto ambiental (de fazer parte de). Ela tem caráter interdisciplinar, pois pode ser considerada uma matéria integradora".

A EA crítica objetiva formação de indivíduos ambientalmente responsáveis, de modo que se comprometam social, histórica e politicamente a construir sociedades sustentáveis (LOUREIRO, TREIN, TOZONI-REIS \& NOVICKI, 2009). De acordo com Reigota (2009), a perspectiva crítica adota a ideia de mudar radicalmente as relações existentes, tanto entre a humanidade quanto entre humanidade e a natureza. Essa EA busca fornecer mecanismos de pró-atividade aos indivíduos para identificarem fragilidades e agirem em suas realidades. 


\section{Análise das concepções por meio da Análise Textual Discursiva de Moraes e Galiazzi}

Com relação às definições de EA dos discentes da Especialização em Educação Ambiental, sujeitos desta pesquisa e que constituíram o corpus de análise deste trabalho, se obteve 51 (cinquenta e um) unidades de significado. Essas unidades registram e indicam as percepções dos pós-graduandos sobre esta temática.

Inicialmente os excertos destas definições foram divididos em 6 (seis) categorias denominadas de Naturalista (1), Utilitarista/Conservacionista (2) Pragmática/ Técnica (3), Histórico-Crítica (4), Educativa (5) e Holística (6). Após reagrupamento das mais próximas, estas unidades de significados puderam ser organizadas em 4 (quatro) categorias finais (Quadro 1), descritas e analisadas na sequência.

Quadro 1 - Total de unidades de significados por categoria.

\begin{tabular}{|c|c|}
\hline Categorias & Total de unidades de significado \\
\hline Naturalista/Holística & 25 \\
\hline Conservacionista/Utilitarista & 3 \\
\hline Pragmática/Técnica & 7 \\
\hline Educativa/Histórico-Crítica & 16 \\
\hline Total & 51 \\
\hline
\end{tabular}

Fonte: Construção dos autores.

Naturalista/Holística - A categoria intitulada Naturalista/Holística foi formada por excertos de "pensamentos" e escritas muito próximas e que possuem similaridades, pontos comuns e complementaridade. De acordo com Sauvé (2005, p. 20):

A tradição da corrente naturalista é certamente muito antiga, se consideramos as "lições de coisas" ou a aprendizagem por imersão e imitação nos grupos sociais cuja cultura está estreitamente forjada na relação com o meio natural. As proposições da corrente naturalista com frequência reconhecem o valor intrínseco da natureza, acima e além dos recursos que ela proporciona e do saber que se possa obter dela.

A mesma autora disserta sobre a Corrente Holística. É preciso levar em conta não apenas o conjunto das múltiplas dimensões das realidades socioambientais como também das diversas dimensões da pessoa que entra em relação com estas realidades, da globalidade e da complexidade de seu "ser-no-mundo":

0 processo de investigação não consiste em conhecer as coisas a partir do exterior, para explicá-las; origina-se de uma solicitação, de um desejo de preservar seu ser essencial permitindo-Ihes revelar-se com sua própria linguagem. Permitir aos seres (as plantas, os animais, as pedras, as paisagens, etc.) falar por si mesmos, com sua própria natureza, antes de encerrar essas naturezas a priori ou logo a seguir em nossas linguagens e teorias, permitirá que nos ocupemos melhor deles (SAUVÉ, 2005, p. 27). 
Nesta interação os registros naturalista/holístico trazem a necessidade de "Inserir o educando no contexto ambiental (de fazer parte de)" (G1), "sensibilização dos indivíduos quanto ao seu lugar" (F6), "o sentimento de pertencimento primeiramente, pois só protegemos e cuidamos daquilo que pertencemos, ambiente que estamos inseridos" (H1). Fica claro nestes excertos que a EA é o processo pelo qual o ser humano deve resgatar, reconectar sua relação com 0 ambiente.

A relação, o olhar, não é algo utilitarista, em benefício próprio, "cuidar dos animais, da nossa água, da mata, enfim, tudo que nos rodeia" (P1), "ato de respeitar todas as formas de vida e cuidar para manter o meio ambiente sempre que possível em ótima sintonia" (K1). 0 cuidar aqui registrado, expressa sinergia, respeito, pois, tudo isso "faz parte da nossa própria essência" (D6). 0 proteger, 0 sentir, o conectar-se vai muito além do externo, anterior a isso, passa pelas reflexões pessoais, interiores, "nosso primeiro ambiente é nosso próprio corpo, pois quem não ama e não respeita seu próprio corpo não aprende a respeitar e valorizar o meio ambiente" (D6).

Segundo Tozoni-Reis (2003), o sujeito natural institui a educação como instrumento de busca do equilíbrio perdido, sendo os conteúdos naturais dos valores/atitudes os principais indicadores da representação da educação relacionada à subjetividade humana:

0 processo pedagógico predominante nessas falas é a "interiorização" dessas atitudes e valores e o conhecimento dos processos ecológicos aparece como instrumento estratégico na interiorização desses valores e atitudes. Outro indicativo das representações de educação nessa perspectiva é ênfase a valores tipicamente humanistas na versão espiritualista (p. 6).

Porém, Layrargues e Lima (2014), em um processo de categorização, denominam esta forma de percepção ambiental como uma macrotendência conservacionista, que se vincula aos princípios da ecologia, na valorização da dimensão afetiva em relação à natureza e na mudança do comportamento individual em relação ao ambiente. São representações conservadoras da educação e da sociedade:

[...] porque não questionam a estrutura social vigente em sua totalidade, apenas pleiteiam reformas setoriais. Apontam para mudanças culturais reconhecidamente relevantes, mas que dificilmente podem ser concretizadas sem que também se transformem as bases econômicas e políticas da sociedade (p. 30).

E continuam na crítica ao definir os pensadores naturalistas como:

[...] comportamentalistas e individualistas, mas a forma conservacionista é uma versão mais ingênua e enviesada de grupos mais ligados às ciências naturais que entendem a crise ambiental e a Educação Ambiental dessa maneira, ora porque não têm uma reflexão sociológica da questão ambiental ora porque entendem que politicamente é melhor não misturar ecologia e política, e neste caso, nos referimos a atores ideologicamente interessados em evitar uma perspectiva de conflito na abordagem da questão (p. 32).

Moraes e Galiazzi (2007, p. 15-16) registram que é importante valorizar a perspectiva dos sujeitos das pesquisas. "A multiplicidade de significados que é possível construir a partir de um mesmo conjunto de significantes tem sua origem nos diferentes pressupostos teóricos que cada leitor adota 
em suas leituras". Os textos segundo os autores são entendidos como "produções linguísticas, referentes a determinados fenômenos e originados em um determinado tempo e contexto".

Ou seja, apesar da impessoalidade dos registros e críticas atribuídas por Layrargues e Lima (2014), ao que denominaram de macrotendência conservadora, pode-se inferir que do ponto de vista de um processo educativo ambiental, nada me concede 0 direito de referir a alguém que pensa a EA como espaço de "Pertencimento" (A1), "respeitando as diferentes vivências e opiniões de cada um [...]" (C1), quem defenda que devemos "[...] cuidar do ambiente onde está inserido, seja ele o ambiente de trabalho, em casa, na escola, no parque (M1)" e que o ambiente "[... é uma dimensão no qual todos nós estamos inseridos como pertencentes a um todo" (R6) e que aqui foi denominado de categoria Naturalista/Holística, como algo menor, ultrapassado, pois a educação não é processo neutro e enquanto espaço de diálogo poderá a curto, médio ou longo prazo proporcionar discursos e reflexões mais atuais para 0 enfrentamento da crise ambiental.

Conservacionista/Utilitarista- A categoria denominada Conservacionista/ Utilitarista foi formada por unidades de significados de escritas que possuem pontos comuns, similaridades e complementaridade, as quais em alguns momentos se confundem e se fundem através da terminologia empregada. Conforme Sauvé (2005, p. 19):

A corrente Conservacionista/Recursista agrupa as proposições centradas na "conservação" dos recursos, tanto no que concerne à sua qualidade como à sua quantidade: a água, o solo, a energia, as plantas (principalmente as plantas comestíveis e medicinais) e os animais (pelos recursos que podem ser obtidos deles), o patrimônio genético [...]. Quando se fala de "conservação da natureza", como da biodiversidade, trata-se sobretudo de uma natureza-recurso. Encontramos aqui uma preocupação com a "administração do meio ambiente", ou melhor dizendo, de gestão ambiental.

De acordo com os excertos extraídos, os registros utilitarista/conservacionista remetem a ideia de que "Não vivemos sem precisar do meio ambiente e com isso necessitamos de cuidar e preservar o que o meio nos dá de graça" (L2), ademais, "preservar o ambiente visando uma melhor qualidade de vida" (J2), com o intuito de "tornarmos estes ambientes agradáveis, saudáveis, limpos, dentre outros" (H2). Podemos observar através das escritas, que neste conceito de EA é bastante forte 0 termo preservação, no sentido de manutenção e busca de melhorias, para benefícios próprios.

No posicionamento de Layrargues e Lima (2014), se percebe quando se referem à macrotendência conservacionista, em alguns pontos, que é minimizada a sensibilidade humana e 0 amor em relação à natureza; que esta surge face à crise ambiental estritamente, e que não compreende as questões sociais, ressaltando não apresentar caráter de criticidade. No entanto, estas características citadas acima e categorizadas como Conservacionista/Utilitarista, têm sua pertinência e não precisam ser rotuladas, especialmente, dependendo da faixa etária e do estágio evolutivo do processo formativo ambiental em que os sujeitos se encontram.

Na classificação realizada por Fernandes et al. (2002), a categoria similar a esta é denominada de "Tradicional", caracterizada como sendo a preocupação com as questões restritas ao ambiente natural. De acordo com os autores, esta possui uma visão antropocêntrica em relação ao meio ambiente; na qual se infere que a relação homem versus natureza seja utilitarista e preservacionista. Ainda, apresenta uma postura conservadora diante dos problemas ambientais; e a EA é tratada como uma disciplina apenas, o que pode levar à perda de suas características interdisciplinares. 
Sauvé (2005), que também se refere à corrente conservacionista/recursista como a "educação para a conservação", menciona que "certamente sempre foi parte integrante da educação familiar ou comunitária nos meios onde os recursos são escassos. [...] ao constatar os primeiros sinais de esgotamento dos recursos depois do "boom" econômico, após a segunda guerra mundial nos países desenvolvidos". Ao contrário do que para Layrargues e Lima (2014), e em nossa categoria que será elucidada posteriormente, são características Pragmáticas, a autora diverge em sua classificação:

Os programas de educação ambiental centrados nos três "R" já clássicos, os da Redução, da Reutilização e da Reciclagem, ou aqueles centrados em preocupações de gestão ambiental (gestão da água, gestão do lixo, gestão da energia, por exemplo) se associam à corrente conservacionista/ recursista. Geralmente se dá ênfase ao desenvolvimento de habilidades de gestão ambiental [...]. Encontram-se aqui imperativos de ação: comportamentos individuais e projetos coletivos (SAUVÉ, 2005, p. 20).

Entretanto, na classificação em três tendências de Tozoni-Reis, a partir de concepções de professores, na categoria equivalente, a do sujeito Natural/Naturalista, "o homem não tem papel de destaque, é apenas mais um elemento da natureza, ou mais uma parte do sistema" e define: "Educação ambiental é a inserção da espécie humana no ambiente, seja ele como membro num ambiente criado pelo homem, seja ele no ambiente natural. Então ele deve se comportar (e esse é um posicionamento bastante forte para nós), deve se colocar como qualquer outra espécie que faz parte do ambiente" (TOZONI-REIS, 2008, p. 24).

Pragmática/Técnica- A categoria intitulada Pragmática/Técnica foi formada por recortes de "pensamentos" e escritas equivalentes, com similaridades e pontos comuns com a Corrente Resolutiva de Sauvé:

A corrente resolutiva surgiu em princípios dos anos 70 , quando se revelaram amplitude, gravidade e aceleração crescente de problemas ambientais. Agrupa proposições em que o meio ambiente é considerado principalmente como conjunto de problemas. Trata-se de informar [...] sobre problemáticas ambientais, como desenvolver habilidades voltadas para resolvê-las. [...] ação: modificação de comportamentos ou de projetos coletivos (SAUVÉ, 2005, p. 21).

A mesma autora registra, também, a existência de uma categoria ambiental denominada de Corrente da Sustentabilidade. Segundo Sauvé (2005), nesta corrente:

[...] 0 desenvolvimento econômico, considerado como a base do desenvolvimento humano, é indissociável da conservação dos recursos naturais e de um compartilhar equitativo dos recursos. Trata-se de aprender a utilizar racionalmente os recursos de hoje para que haja suficientemente para todos e se possa assegurar as necessidades do amanhã. A educação ambiental torna-se uma ferramenta, entre outras, a serviço do desenvolvimento sustentável (p. 37).

Porém, vale registrar que, segundo Vizeu, Meneghetti e Seifert (2012), na era moderna - cuja estrutura política vigente é o capitalismo - vários conceitos emergem com o propósito de reafirmação do sistema social e político dominante: democracia, desenvolvimento, progresso, competitividade e mais recentemente desenvolvimento sustentável, e que este emerge: 
[...] de condições particulares de contradição do sistema capitalista, uma vez que, no surgimento da ideia de sustentabilidade, destacam-se os efeitos nocivos que 0 avanço desse sistema trouxe para o planeta, particularmente, para a questão ecológica. [...] o principal intento é dissipar a névoa que desvia a atenção sobre os problemas reais e cada vez mais agudos da prática econômica capitalista, névoa esta que cria uma falsa noção de conciliação entre o capitalismo e a questão ecológica (p. 570).

Conforme a classificação de Macrotendência Pragmática, estabelecida por Layrargues e Lima (2014), esta vertente surge mundialmente no decorrer da década de 1980, sendo considerada uma derivação ainda não tão nítida da vertente conservacionista, a partir inicialmente da problemática do resíduo urbano-industrial nas cidades, como tema cada vez mais utilizados nas práticas pedagógicas. Esta descrição vem ao encontro de alguns registros observados, conforme trechos do metatexto apresentado a seguir.

A partir das unidades de significados, os registros pragmático/técnico, demonstram ênfase em "Reciclar" (M3); "Instigar nas pessoas ser responsável desde a separação adequada do lixo em nossa casa, até a poluição do rio que abastece nossa cidade" (H3), mencionando que "cada um tem suas obrigações para manter esse todo em equilibrio" (R3), através da "atuação diante dos impactos que estamos enfrentando" (B3).

Percebe-se nestes registros, características de ação, de tomada de decisões, de desenvolver habilidades, objetivando uma possibilidade de desenvolvimento sustentável na questão da destinação de resíduos, sob a forma da reciclagem. Complementando esta visão, "ligado a comportamento" (B3), "trabalho coletivo, mudanças de hábitos e costumes" (03). Salienta-se a menção da EA enquanto "Cuidar da gestão de uma empresa" (M3) e ainda como maneira "principalmente de reconstrução" (A3).

Os questionamentos de Layrargues e Lima (2014) apontando a falta de reflexão quanto às causas e os sujeitos envolvidos nos impactos ambientais, como geração indiscriminada de resíduos, não impede que os excertos acima, categorizados como Pragmáticos/técnicos, tenham sua relevância na construção de uma identidade ambiental e futuramente ressignificar seu posicionamento na sociedade.

Neste sentido, Fernandes et al. (2002), classifica como "Resolução de Problemas" a utilização de forma racional do meio ambiente levando em consideração aspectos de desenvolvimento sustentável e de gestão ambiental. Os autores trazem como crítica, que nesta categoria os problemas ambientais são trabalhados de forma superficial. Não levando em conta todos os aspectos envolvidos nos mesmos, como por exemplo, as causas do excesso de resíduos gerados pelo consumismo e capitalismo. Também considera a Educação Ambiental como uma disciplina isolada.

Ademais, no início da década de 1990, ocorreu um estímulo à vertente pragmática, da resolução de problemas nas atividades em EA, acompanhada da responsabilização individual dos problemas ambientais, fruto da lógica do "cada um fazer a sua parte" como contribuição cidadã ao enfrentamento da crise ambiental. Isso resultou no estímulo à mudança comportamental nos hábitos de consumo, dando impulso à esta macrotendência, tendo forte adesão de educadores ambientais. Assim, a atenção focada exclusivamente na questão dos resíduos, coleta seletiva e reciclagem, se amplia para o Consumo Sustentável (LAYRARGUES, 2012). Estas características surgem nos recortes das escritas analisadas.

Por outro lado, Tozoni-Reis define uma outra tendência denominada como sujeito Cognoscente/ racional, expressando a ideia de que "a intervenção predatória do homem pode ser modificada pelo avanço do conhecimento científico" (TOZONI-REIS, 2008, p. 25). Nesta tendência, "0 conhecimento 
aparece como mediador da relação homem-natureza, mas uma mediação imediata, direta, automática, mecânica, como se fosse assim: conheceu... preservou." (TOZONI-REIS, 2008, p. 29). Expressa a ideia de que a educação tem caráter fortemente informativo; este pensamento direciona ao desenvolvimento de habilidades e tomada de decisões, mesmo que em muitos momentos seja meramente com intuito de remediar, na busca de soluções aos desequilíbrios ou desastres ambientais.

Educativa/Histórico-Crítica- A categoria intitulada Educativa/Histórico-Crítica foi formada por excertos de percepções e escritas muito próximas, que possuem similaridades, pontos comuns e complementaridade.

Dentre as categorizações pode-se destacar a corrente Crítica Social sugerida por Sauvé (2005, p. 30): "[...] análise das dinâmicas sociais que se encontram na base das realidades e problemáticas ambientais: análise de intenções, de posições, argumentos, de valores explícitos e implícitos, de decisões e ações dos diferentes protagonistas de uma situação", entre os protagonistas, o discente; o qual é convidado a refletir sobre projetos, sua essência, para assim aclarar sua razão de ser e seu significado e para descobrir o que se aprende realizando tal ação.

A autora aponta além desta, a corrente Humanista, que corresponde a um meio de vida, com suas dimensões históricas, culturais, políticas, econômicas, estéticas, entre outras; não podendo ser abordado sem se levar em conta sua significação, seu valor simbólico. "[...] criação de um projeto de pesquisa que busque compreender melhor um aspecto particular ou uma realidade específica do meio de vida; a fase de pesquisa como tal, aproveitando os recursos que são o próprio meio [...] o saber do grupo: os conhecimentos e os talentos de cada um são aproveitados" (SAUVE, 2005, p. 25-26).

Assim, das relações entre os registros educativo/histórico-crítico emerge que a "educação ambiental tem uma dimensão política, social, cultural, tudo que envolve o meio onde estamos inseridos, não só o ambiente, mas a casa, a escola, a sociedade como um todo" (C4). E convida à "reflexão das ações cotidianas e atuação diante dos impactos que estamos enfrentando, para que promova mudanças" (B4). Como características inerentes "Ela tem caráter interdisciplinar, pois pode ser considerada uma matéria integradora" (G4).

A partir da análise dos excertos se compreende que esta vertente tem um universo muito maior do que preservar, conservar, reciclar apenas; levando em consideração toda a amplitude do contexto do educando, na busca do desenvolvimento de habilidades e atitudes crítico-reflexivas.

Ao encontro disto, a macrotendência crítica (LAYRARGUES \& LIMA, 2014, p. 33) "aglutina as correntes da Educação Ambiental Popular, Emancipatória, Transformadora e no Processo de Gestão Ambiental"; as quais "[...] se constroem em oposição às tendências conservadoras, procurando contextualizar e politizar o debate ambiental, problematizar as contradições dos modelos de desenvolvimento e de sociedade". É uma vertente dialógica, contrária à simples transmissão de conhecimento, que forma autores das próprias histórias; indivíduos ambientalmente responsáveis, comprometidos social, histórica e politicamente, para construir sociedades sustentáveis. Ainda, inclui saberes filosóficos e culturais, e tem caráter interdisciplinar.

Sauvé (2005, p. 26) discorre também sobre a corrente Moral/Ética:

[...] relação com o meio ambiente é de ordem ética: é, pois, neste nível que se deve intervir de maneira prioritária. 0 atuar se baseia num conjunto de valores, mais ou menos conscientes e coerentes entre eles. [...] desenvolvimento moral dos alunos, em vínculo com o desenvolvimento do raciocínio sociocientífico. Trata-se de favorecer a confrontação em situações morais que levam a fazer suas próprias escolhas e 
a justificá-las: o desenvolvimento moral opera, em diversas situações, por meio do "conflito moral", do confronto, às vezes difícil com as posições dos outros.

A autora em sua classificação, caracteriza ainda a denominada corrente da Eco-educação: "Esta corrente está dominada pela perspectiva educacional da educação ambiental. Não se trata de resolver problemas, mas de aproveitar a relação com o meio ambiente como cadinho de desenvolvimento pessoal, para o fundamento de um atuar significativo e responsável” (SAUVÉ, 2005, p. 35).

Neste sentido, a interação dos registros educativa/histórico-crítico leva em consideração "conscientizar e educar primeiramente a sociedade [...]. Sociedade sem educação, não existe preservação e educação ambiental" (E5); "Conscientizar o homem" (M5). Compreendem que "é uma área de ensino-aprendizagem com o objetivo de transmitir conhecimento" (Q5); "ter novos conhecimentos para poder transmitir, o resultado seja multiplicado" (05).

Neste caso, parece claro que apesar da utilização do termo "transmitir", a intenção prioritária possivelmente foi no sentido de acesso à informação; "se refere a ensinar o indivíduo" (M5). Os excertos trazem a necessidade de "procurar aprender e passar os princípios que auxiliem na preocupação com preservação de qualquer tipo por em prática a ética humana" (I5), "o aprender e compreender o que é, como fazer" (C5). Do ponto de vista de um processo educativo ambiental "parte do pressuposto de uma ação que vise sensibilizar os cidadãos a respeito das questões envolvendo o ambiente" (K5), "desde pequenos precisamos conhecê-Io" (D5). Pode-se inferir através destas escritas, que neste conceito de Educação Ambiental ficam evidentes as reflexões ambientais e suas relações pessoais.

Segundo Fernandes et al. (2002), a categoria denominada de "Integradora" conduz a uma visão globalizadora homem/sociedade/meio ambiente; a Educação Ambiental é concebida como processo de formação de valores, ideias e posturas. Os ecossistemas emergem como redes, e o ser humano como parte do planeta. A EA deve ser desenvolvida como projeto conscientizador, com atividades interdisciplinares.

Todavia, em complementaridade, na classificação de Tozoni-Reis, a autora evidencia o sujeito Histórico, onde "a relação homem-natureza é entendida como sociedade-natureza" (TOZONI-REIS, 2008, p. 27). "A ideia síntese é que essa relação é construída pelas relações sociais: a história e a cultura são condicionantes e mediadoras, conferindo-lhe um caráter sócio-histórico" (TOZONI-REIS, 2008, p. 30). Nesta tendência a EA é o estudo da relação consciente com a natureza e da dimensão histórica e filosófica com essa natureza.

Sauvé $(2005$, p. 17) alerta para uma questão muito importante que, está relacionada ao fato de que: "Cada um predica sua própria visão e viu-se, inclusive, formarem-se "igrejinhas" pedagógicas que propõem a maneira "correta" de educar, "o melhor" programa, o método "adequado". Ao se encerrar este processo de categorização, via "Análise Textual Discursiva" (MORAES \& GALIAZZI, 2007), se busca por uma modalidade de categorização que leve em consideração o tempo e a diversidade das áreas de formação que se traduz em uma riqueza de discursos e práticas, que não são neutras, mas que são processos e enquanto "caminhar" não está pronto, podendo e devendo ser revistas.

\section{A Educação Ambiental, sua Interdisciplinaridade e Temas transversais}

Em 1977, a Conferência Intergovernamental de Tbilisi, ocorrida na Geórgia (antiga União Soviética) organizada pela Organização das Nações Unidas para a Educação, Ciência e Cultura (UNESCO) e Programa das Nações Unidas para o Meio Ambiente (PNUMA) traz em uma de suas recomendações: 
A educação ambiental é o resultado da reorientação e articulação de diferentes disciplinas e experiências educacionais que facilitam uma percepção integrada dos problemas do meio ambiente, possibilitando ações mais racionais, capazes de atender às necessidades sociais (MMA, 2018, s/p.).

Mesmo não sendo recente, este evento histórico, demonstra com essa afirmação, que já naquele momento a recomendação era para que 0 ensino de Educação Ambiental fosse a partir da interdisciplinaridade.

Nos anos 1990, a Organização das Nações Unidas (ONU) realizou no Rio de Janeiro, a Conferência das Nações Unidas sobre o Meio Ambiente e Desenvolvimento, realizada em 1992, que ficou conhecida como "Eco ou Rio 92". Segundo Dias (2000), as metas priorizadas no evento reiteraram os objetivos de Tbilisi, sobre a necessidade de a EA ser exercitada interdisciplinarmente, ressaltando a importância de: I- reorientar a EA para o desenvolvimento sustentável; II- proporcionar informações sobre o meio ambiente, de forma a conscientizar a população sobre os problemas que estavam ocorrendo no planeta; III) promover a formação de professores na área de EA.

Em 1999, a Lei $n^{\circ} 9.795$ estabelece em seu Art. $8^{\circ}$ que: As atividades vinculadas à Política Nacional de Educação Ambiental (PNEA) devem ser desenvolvidas na educação em geral e na educação escolar; § $3^{0}$ : As ações de estudos, pesquisas e experimentações voltar-se-ão para: I - 0 desenvolvimento de instrumentos e metodologias, visando à incorporação da dimensão ambiental, de forma interdisciplinar, nos diferentes níveis e modalidades de ensino (BRASIL, 1999).

0 enfoque interdisciplinar, presente na referida Lei é reforçado nas Diretrizes Curriculares Nacionais (DCN) de EA em seu Art. 80: A EA, respeitando a autonomia da dinâmica escolar e acadêmica, deve ser desenvolvida como uma prática educativa integrada e interdisciplinar, contínua e permanente em todas as etapas, níveis e modalidades, não devendo, como regra, ser implantada como disciplina isolada ou componente curricular específico (BRASIL, 2012).

Para Adams (2012), devido à importância dos conceitos, cabe discutir a legitimação da EA no país, analisando em relação ao seu conteúdo e à relevância para docentes da educação formal. A intenção é incentivar aos professores, de todos os níveis, terem conhecimento da Lei de Educação Ambiental e suas Diretrizes, e de uma análise crítica sobre estes documentos para auxiliar na perpetuação de ações que possibilitem a prática da EA de forma articulada, interdisciplinar e com abordagem crítica, voltada para o desenvolvimento de uma sociedade sustentável.

Outra tentativa de legitimar e reforçar a EA como prática interdisciplinar, se explicita formalmente na obrigatoriedade constitucional, com sua inclusão nos Parâmetros Curriculares Nacionais (PCN); um instrumento legal e documento governamental, como a Lei 9.795, que assegura para a temática um caráter transversal, indispensável e indissociável da política educacional brasileira (FURTADO, 2009).

Mas afinal, como podemos conceituar interdisciplinaridade? Na década de 1960, na França, estudantes pedem uma reforma na Educação através da ciência como humanista e não fragmentada. No Brasil, Hilton Japiassu e Ivani Fazenda tratam do tema, a partir das reformas de ensino, mas apenas em 1996 a interdisciplinaridade se estabelece nos documentos oficiais, e ainda hoje é uma discussão complexa e difícil de elucidar para muitos profissionais da educação.

Segundo Fazenda (2002), interdisciplinaridade não é apenas uma integração entre disciplinas, mas entre sujeitos que dialogam e se encontram, que estabelecem parcerias, um movimento de interação daqueles que percebem que precisam do outro, de outros, pois se sentem partes de um movimento em busca da totalidade. 
Ainda de acordo com Fazenda (2008):

A interdisciplinaridade é muito mais do que um conjunto de disciplinas, é uma libertação de modelos predeterminados, é saber unir a arte com a ciência, é saber usar a utilidade do tempo; é uma relação entre pessoas, que começa a partir de um olhar, que pode gerar um momento único de interação, um momento de aprendizagem. Professores e alunos são sujeitos com histórias de vida e bagagens culturais diversas, que vivenciam situações, por vezes, antagônicas. Este vínculo, necessário à prática interdisciplinar, demanda um intenso e responsável trabalho pedagógico (p. 86).

Na concepção de Lück (2010), a interdisciplinaridade é um processo que envolve a integração e 0 engajamento entre os professores, por meio de um trabalho coletivo de interação das disciplinas do currículo escolar, possibilitando dessa maneira superar a fragmentação dos conhecimentos científicos.

A interdisciplinaridade é um movimento de construção do conhecimento holístico, onde diferentes áreas do saber compartilham relações de reciprocidade, mutualidade e de substituição da concepção fragmentária. É algo a ser vivida, enquanto atitude de espírito, feita de curiosidade, do senso de aventura e descoberta, exercendo um movimento de relações, sendo uma prática individual e coletiva, onde o diálogo é a atitude de abertura com outras disciplinas, reconhecendo a necessidade de aprender com as outras áreas do conhecimento (JAPIASSU, 1992).

Mais além dos conceitos de interdisciplinaridade, como efetivá-la nos espaços de ensino? De acordo com Araújo (2003) poderia ser através do desenvolvimento de Projetos, de Temas Transversais presentes nos PCN. Ou ainda, do planejamento a partir de situações problemas; da avaliação permanente dos professores e da gestão; da autonomia de ação docente; de ações coletivas; de formação intelectual/cognitiva e cidadã.

Porém, antes deste processo de efetivação curricular, faz-se necessário tratar da conceituação em processos de formação continuada, visto que muitos professores ainda confundem interdisciplinaridade, com multidisciplinaridade e pluridisciplinaridade, conforme também pode ser observado nestes discentes pelos registros abaixo:

A6: "Quando se faz uso de mais de uma ciência no ensino de determinado conteúdo ou contexto".

A14: "É trabalhar um assunto, como por exemplo Educação Ambiental, em todas as disciplinas".

A2: "A interdisciplinaridade permite a interação, trocas de experiências e vivências, assim como busca um olhar na totalidade dos conhecimentos, para uma ação mais eficaz na atuação das metodologías”.

A4: "Interdisciplinaridade é uma dinâmica interativa em que as disciplinas curriculares dialogam entre si, se relacionam".

Além de alguns exemplos de conceituação inadequada ou incipiente da interdisciplinaridade no espaço escolar, com relação à EA, ainda persiste uma prática que carece de maior compreensão quanto à sua aplicação interdisciplinar a ser incluída no processo educacional vigente. Uma nova tentativa de reforçar a legitimidade da EA surge com a homologação das DCN da EA, a qual indica a sua efetividade para a Educação Básica em todas as suas etapas e modalidades reconhecendo a relevância, obrigatoriedade e legitimação da EA. Considerada um componente essencial e permanente 
da educação é fundamental que docentes tenham acesso à lei e demais documentos que a legitimam (ADAMS, 2012).

Oliveira (2009) investigou como está sendo aplicada a EA na escola e concluiu: "os professores não citam a lei, contudo, acreditam que a temática deve ser trabalhada", revelando que esta ferramenta importante para a compreensão da EA não era conhecida como deveria. A pesquisa traz outro resultado que confirma a necessidade de divulgação para aprimorar e disseminar essa prática educacional: "a temática ambiental está presente no trabalho dos docentes e no material didático, mas não é trabalhada interdisciplinarmente como determina a legislação".

Estas constatações indicam causas da dificuldade de implementação da EA no sistema de ensino, e equivocadamente é percebida como ensino da Ecologia ou deve ser tratada na disciplina de Ciências, justamente por falta de conhecimento de referenciais teóricos. Medina (2001) acrescenta a essas dificuldades formas muitas vezes simplistas com que tem sido concebida e aplicada a $E A$, reduzindo-a a processos de sensibilização e percepção ambiental em conteúdo da área biológica, ou atividades pontuais no Dia do Meio Ambiente, do Índio, da Árvore e visitas a parques e reservas. Não se nega a necessidade dessas atividades, mas são insuficientes para desenvolver conhecimentos e valores postulados nos PCN de Meio Ambiente e de Ética.

Ainda, Reis Júnior (2003) afirma que existem obstáculos na EA dos estudantes, "culpando" parte dos educadores por diminuírem a importância do tema, caracterizando o tratamento superficial e suas inaptidões. Consequentemente limitam-se no desenvolvimento restrito de livros didáticos e calendários comemorativos que não deveriam ser enxergados como métodos exclusivos de abordagem, impossibilitando a rica possibilidade de contextualização, desvinculando conteúdo da realidade do aluno.

Além de uma crítica à lei, pela visão antropocêntrica de meio ambiente, referindo-se a este como bem consumível, contrariando os princípios da EA proclamados na Carta da Terra, e no Tratado de Educação Ambiental para Sociedades Sustentáveis e Responsabilidade Global, importantes documentos elaborados no Fórum das ONGs, evento paralelo à "Rio 92"; esta não faz nenhuma referência ao tipo de impacto que empresas e cidadãos podem causar no meio, demonstrando certa omissão em relação à nossa responsabilidade. Ao trabalhar a referida lei com professores pode-se abordar a questão do antropocentrismo, a fim de promover uma reflexão aprofundada sobre enfoques que podem trazer contradição, aprimorando o senso crítico dos docentes e posteriormente poderem estimular os estudantes (FURTAD0, 2009).

A partir do exposto compreende-se que a EA é um processo de educação, e não apenas uma disciplina. Trata-se de uma prática pedagógica interdisciplinar, que deve ser desenvolvida em todos os níveis de ensino, da Educação Infantil à Superior, nos diferentes contextos educacionais; explícito nos principais documentos referência, destacando a Lei 9.795, apesar de alguns educadores não conhecerem.

Esta é uma discussão extremamente complexa e infinita até o momento, pois sem uma disciplina específica a temática pode ser posta de lado "algo que é de todos acaba sendo de ninguém", deixando de ser trabalhada. Por outro lado, apesar da EA se caracterizar interdisciplinarmente, na prática suas ações acabam por ser dificultadas, seja pela questão de recursos escassos e pela logística de saídas a campo para reconhecimento do cotidiano dos discentes. Além das dificultade e disponibilidade de educadores de distintas formações em se envolverem e executarem esses projetos conjuntamente, e inclusive pela pressão em serem vencidos os conteúdos programáticos impostos.

Com relação à transversalidade enquanto temática educacional, atualmente, as instituições de ensino carregam a principal fonte e forma de conhecimento sobre EA a serem construídas durante a 
formação da concepção dos estudantes, considerando os temas transversais, por exemplo, o tema Meio Ambiente, presentes nos PCN. A respeito da EA, os PCN deixam claro que:

A preocupação em relacionar a educação com a vida do aluno, em seu meio, sua comunidade, não é novidade; e vem crescendo em especial desde a década de 60 no Brasil. [...] Porém, a partir da década de 70, com o crescimento dos movimentos ambientalistas, passou-se a adotar explicitamente a expressão "Educação Ambiental" para qualificar iniciativas de universidades, escolas, instituições governamentais e não governamentais, por meio das quais se busca conscientizar setores da sociedade para questões ambientais (BRASIL, 1997, p. 181).

A EA desenvolvida de forma transversal e articulada junto aos eixos temáticos dos currículos dos cursos de licenciatura poderá promover uma formação interdisciplinar e rica de significados, colaborando para a profissionalização do futuro professor e tornando-o capaz de ações transformadoras em favorecimento das questões ambientais. A inserção deste tema como transversal foi um avanço no currículo, possibilitando a ação interdisciplinar indispensável em seus componentes, provocando que esta temática não seja desenvolvida isoladamente, promovendo contextualização com os estudantes. Portanto, nos PCN sobre a influência da EA na transformação social:

[...] ressalta-se que, embora recomendada por todas as conferências internacionais, exigida pela Constituição e declarada como prioritária por todas as instâncias de poder, a Educação Ambiental está longe de ser uma atividade tranquilamente aceita e desenvolvida, pois implica mudanças profundas e nada inócuas. Ao contrário, quando bem realizada, a EA leva a mudanças de comportamento pessoal e, atitudes e valores de cidadania que podem ter fortes consequências sociais (BRASIL, 1997, p. 23).

Ainda, conforme Beane (2003), a interdisciplinaridade é um mecanismo de executar e articular os TT com diferentes áreas do conhecimento e atores sociais que se encontram e contribuem para o processo formativo. Transpondo a interdisciplinaridade para a temática ambiental, segundo Bernardes e Prieto (2010), se há críticas quanto à dificuldade de implantação da EA de forma interdisciplinar e transversal nas escolas e universidades, é necessário reconhecer por outro lado, que a questão ambiental não é, nem pode ser um conhecimento em si, independente das áreas afins.

Neste sentido, 0 artigo 16 das DCN para Educação Ambiental registra que a inserção dos conhecimentos relativos à EA nos currículos da Educação Básica e da Educação Superior pode ocorrer: I - pela transversalidade, mediante temas relacionados com o meio ambiente e a sustentabilidade socioambiental [...] (BRASIL, 2012). Porém, mediante a dificuldade de praticar a transversalidade, Cuba (2010) defende que a EA deve ser tratada de modo científico, oferecida em forma de disciplina específica, porém sem perder sua essência holística interdisciplinar.

Com relação aos temas transversais, assim como as conceituações de EA e Interdisciplinaridade, observa-se, pelos registros dos sujeitos da pesquisa, uma diversidade e heterogeneidade de discursos, com conceituações incipientes e outras mais elaboradas, exemplificadas a seguir.

Conceituação incipiente:

A5: "Estuda a transversalidade dos conteúdos".

A9: "Temas transversais, utilizados para envolver e encaixar disciplinas". 
Conceituação mais elaborada:

A10: "Temas transversais são temas que não são especificamente pertencentes a uma determinada disciplina, mas que perpassam todas as disciplinas, podendo ser trabalhados em qualquer matéria por qualquer professor. Exemplo: Educação Ambiental, igualdade de gênero..."

A11: "Temas transversais: São temas que devem perpassar por todas as áreas do currículo escolar, ou seja, ser discutido em todas as disciplinas, um exemplo disso é a educação ambiental".

Igualmente à formação docente continuada sobre a correta conceituação de interdisciplinaridade, os temas transversais também necessitam ser discutidos de forma prévia à discussão mais específica sobre estes, em função de conceituações incipientes, como observa-se nas respostas de estudantes da especialização em Educação Ambiental.

\section{CONSIDERAÇÕES FINAIS}

0 estudo das percepções de Educação Ambiental deste grupo, teve relevância uma vez que são futuros especialistas na área de Educação Ambiental, e assim sendo, avaliar seus olhares sobre 0 tema poderá contribuir para a definição de ações que fortaleçam os processos formativos.

Após análise das percepções pode-se inferir que as respostas trazem diferenças consideráveis entre 0 grupo investigado, sendo que as diferenças apresentadas nos remetem à importância da discussão da temática ambiental, principalmente levando em consideração as distintas áreas do conhecimento, reflexo da diversidade na formação inicial destes discentes. Estes resultados corroboram com os registros de diferentes autores que configuram a EA, não como um conceito científico $\mathrm{e}$ sim uma representação social. No entanto, houve consenso quanto à necessidade e à relevância das discussões sobre as questões ambientais em sua formação, como discente e profissional.

As múltiplas correntes de EA, conceitos, práticas e metodologias, não foram diferenciadas facilmente; mas apesar do receio de que as tipologias simplificam a realidade, perdem de vista seu dinamismo e causam um estranhamento entre os atores que compartilham o campo, percebeu-se benefícios ao analisá-las, pois a interpretação da realidade trouxe resultados positivos.

Por meio da classificação de Layrargues e Lima (2014) identificou-se dificuldade em categorizar percepções dos discentes integralmente. As respostas foram agrupadas de acordo com intencionalidade de forma geral. A macrotendência conservacionista foi pautada no sentimento de pertencimento, preservação e inserção do ser humano no meio para equilíbrio e qualidade de vida. Esta tendencia, caracterizada como dominante até a década de 1990, ainda se apresenta de forma predominante entre as definições.

As concepções alocadas na macrotendência pragmática também foram expressivas, e está relacionada à comportamento, atuação diante dos impactos, reciclagem, trabalho coletivo, mudança de hábitos e costumes. Esta poderia adquirir um caráter crítico se incorporasse ao seu discurso análises sociais, econômicas, culturais e políticas, na problemática dos resíduos sólidos, por exemplo; no entanto, não considera a relação entre os problemas ambientais, suas causas e responsáveis. Poucas escritas apresentaram caráter crítico, dentre estas destacou-se a dimensão política, social e cultural, inserção do educando no contexto ambiental, educação global, interdisciplinaridade e integração. 
Através da categorização via Análise Textual Discursiva, buscou-se por uma modalidade que considerasse a diversidade das áreas de formação que se traduz em uma riqueza de discursos, visões e práticas pedagógicas; que é um processo, não está pronto e pode ser reconstruído; que não propõe uma maneira "correta" de educar, "o melhor" programa, o método "adequado" e que para atender os diferentes enfoque, exigiu um número maior de categorias.

0 conceito de EA, durante longo período, teve enfoque naturalista, estritamente ambiental, priorizando a vida biológica e natureza, com esta sendo tratada de forma independente da interação com o mundo; onde aspectos sociais, políticos, culturais e econômicos e suas interações, não estavam contemplados. Entretanto, pode-se inferir ainda a prevalência dos excertos na categoria estabelecida como Naturalista/holística; onde salienta-se sensibilização dos indivíduos quanto ao seu lugar, o sentimento de pertencimento, proteção, cuidado. 0 resgate e reconexão de sua relação com 0 ambiente não é algo utilitarista, em benefício próprio, é tudo que nos rodeia, respeitar todas as formas de vida, sintonia, sinergia, essência, reflexões pessoais e interiores.

Em menor proporção, mas ainda de modo expressivo, foram observados registros categorizados como educativo/histórico-críticos, nos quais a EA apresenta uma dimensão política, social e cultural, aborda a reflexão das ações cotidianas para a promoção de mudanças. Além de possuir caráter interdisciplinar, sendo considerada uma matéria integradora, envolvendo o contexto do educando, na busca do desenvolvimento de habilidades e atitudes crítico-reflexivas. A interação na categoria educativa/histórico-crítica considera a conscientização, a educação da sociedade, 0 ensino-aprendizagem objetivando novos conhecimentos e que estes sejam multiplicados. Prioriza a ética humana, compreensão, cidadania e relações pessoais.

Sobre a utilização da ATD, pode-se ressaltar suas características peculiares e benéficas, enquanto metodologia, que permitem analisar o todo em partes. Com isso, percebe-se a impossibilidade de classificar o pensamento de um indivíduo em categoria única, pois somos seres mutáveis, adaptáveis, em processo de construção e inacabados, em constante aprendizagem, convivendo em sociedade sob diversas influências e em busca de novos conhecimentos. Seria inatingível e simplista tentar "rotular" e comparar percepções ambientais, que em alguns momentos se confundem e complementam; ou ainda tentar julgar e definir o que é certo ou errado. As categorias finais da ATD só foram possíveis de serem construídas a partir dos excertos advindos dos discursos, demonstrando que a nossa expressão é algo em movimento e em formação.

No que diz respeito à interdisciplinaridade e temas transversais da temática ambiental, desde a década de 1970 inúmeros são os debates e sua recomendação, visto que a EA articula diferentes disciplinas que percebem integralmente os impactos ambientais e sociais, atuando de modo efetivo. É 0 diálogo entre sujeitos que se complementam, interagem, estabelecem parcerias, formando a totalidade, evitando a fragmentação dos conteúdos. Apesar da importância destas discussões no processo de formação continuada, pode-se observar que alguns professores ainda confundem as definições destes termos ou os identificam de maneira superficial e descontextualizada.

Por fim, a EA desenvolvida transversalmente, de forma articulada, com formação interdisciplinar nos currículos, colabora para a profissionalização do futuro professor e o capacita como agente transformador. Devido a conceitos incipientes percebidos, os temas transversais devem ser debatidos mais profundamente também. Por outro lado, foram observadas algumas conceituações elaboradas, com exemplificações e aplicabilidade. 


\section{REFERÊNCIAS}

ADAMS, B. G. A importância da lei 9.795/99 e das diretrizes curriculares nacionais da educação ambiental para docentes. REMOA/UFSM, v. 10, n. 10, p. 2148-2157, 2012.

ARAÚJO, U. F. Temas transversais e as estratégias de projetos. São Paulo: Moderna. 2013.

BRASIL. Lei n⿳0 9.795 de 27 de abril de 1999 institui a Política Nacional de Educação Ambiental. Diário Oficial da República Federativa do Brasil, MEC, Brasília, DF, 1999.

BRASIL. Resolução $\mathbf{n}^{0}$ 2, 15 de junho de 2012, estabelece as Diretrizes Curriculares Nacionais para a Educação Ambiental. MEC, CNE, DOU nº 116, Seção 1, p. 70-71, 2012.

BRASIL. Introdução aos Parâmetros Curriculares Nacionais. Brasília: MEC. 1997. Disponível em: https://bit.ly/ 3sFXeD4. Acesso em: 19 nov. 2018.

CARVALHO, I. C. M. Educação Ambiental Crítica: nomes e endereçamentos da educação. In P. P. Layrargues, Identidades da educação ambiental brasileira, Brasília, Brasil, 2004, p. 13-24.

COIMBRA, D. B. Abordagens e Limitações da Educação Ambiental no Ensino Superior: percepções a partir da disciplina de gestão ambiental nos cursos de graduação em Administração na cidade de Fortaleza/CE. Tese de Doutorado em Educação, Universidade Federal do Ceará, Brasil, 2011. Disponível em: https://bit.ly/3j6tM5U. Acesso em: 14 mai. 2018.

CUBA, M. A. Educação ambiental nas escolas. ECCOM, v. 1, n. 2, p. 23-31, 2010.

DIAS, G. F. Educação ambiental: princípios e práticas. São Paulo: Gaia, 2000.

FAZENDA, I. C. A. 0 que é Interdisciplinaridade? São Paulo: Cortez, 2008.

FERNANDES, E. C.; CUNHA, A. M. de 0.; MARÇAL, 0. Educação Ambiental e Meio Ambiente: concepções de profissionais da educação. In: IV Encontro nacional de pesquisa em educação em ciências. São Carlos, Brasil, 2002.

FREIRE. P. Educação e Mudança (12ª ed.). São Paulo: Paz e Terra, 1979.

FURTADO, D. J. Os caminhos da educação ambiental nos espaços formais de ensino-aprendizagem: qual o papel da política nacional de Educação Ambiental? Rev. Eletrônica do Mestrado em Educação Ambiental, v. 22, p. 337-353, 2009.

GRÜN, M. Ética e Educação Ambiental: a conexão necessária. São Paulo: Papirus, 1996.

JAPIASSU, H. A atitude interdisciplinar no sistema de ensino. Revista Tempo Brasileiro, v. 108, p. 83-94, 1992.

LAYRARGUES, P. P.; LIMA, G. F. C. As macrotendências político-pedagógicas da educação ambiental brasileira. Ambiente \& Sociedade, v. 17, n. 1, p. 23-39, 2014.

LOUREIRO, C. F. B. Educação Ambiental: no consenso um embate? (5. ed.). Campinas: Papirus, 2007. 
MORAES, R.; GALIAZZI, M. C. Análise textual discursiva. ljuí: Editora Unijuí, 2007.

NASCIMENTO, S. Concepções e representações sociais de meio ambiente: uma revisão crítica da literatura. In: VII ENPEC - Encontro Nacional de Pesquisa em Educação em Ciências. Florianópolis, Brasil, 2009.

OLIVEIRA, M. M. Como fazer pesquisa qualitativa. Petrópolis: Vozes, 2007.

REIGOTA, M. Meio ambiente e representação social. São Paulo: Cortez, 2004.

REIS JÚNIOR, A. M. A formação do professor e a Educação Ambiental. Campinas, 2003.

SAUVÉ, L. Uma cartografia das correntes de Educação Ambiental. In: SATO, M.; CARVALHO I. C. M.(Org) Educação Ambiental: pesquisas e desafios, Porto Alegre: Artmed, 2005, p. 17-44.

TOZONI-REIS, M. F. C. Pesquisa-ação em Educação Ambiental. Pesquisa em Educação Ambiental, v. 3, n. 1, p. 155-169, 2008.

SILVA, M. J.; SILVA, G. C.; TREVISAN, I. Representações sociais de meio ambiente: um estudo com licenciandos de diferentes cursos da UEPA, campus Altamira. Revista de Educação em Ciências e Matemática, v. 11, n. 21, p. 92-105, 2014.

VIZEU, F.; MENEGHETTI, F. K.; SEIFERT, R. E. Por uma crítica ao conceito de desenvolvimento sustentável. Cadernos EBAPE. BR, v. 10, n. 3, p. 569-583, 2012.

RECEBIDO EM: 04 dez. 2020

CONCLUÍDO EM: 31 jul. 2021 